\title{
ERRATUM
}

Joseph B. Whalen $\cdot$ John A. Percival

Vicki J. McNicoll · Frederick J. Longstaffe

\section{Intra-oceanic production of continental crust in a Th-depleted ca. 3.0 Ga arc complex, western Superior Province, Canada}

\section{Contrib Mineral Petrol (2003) 146:78-99}

In the original online publication of this article, Table 4 was unfortunately omitted. We apologise for this mis- take. The correct version of Table 4 with all parts included, can be seen here.

The online version of the original article can be found at http:// dx.doi.org/10.1007/s00410-003-0484-8

J. B. Whalen $(\bowtie) \cdot$ J. A. Percival · V. J. McNicoll Geological Survey of Canada, 601 Booth Street, Ottawa, ON,

K1A OE8, Canada

E-mail: jwhalen@gsc.NRCan.gc.ca

Tel.: + 1-613-9954972

Fax: + 1-613-9957997

F. J. Longstaffe

Department of Earth Sciences,

The University of Western Ontario,

London, ON, N6A 5B7, Canada 


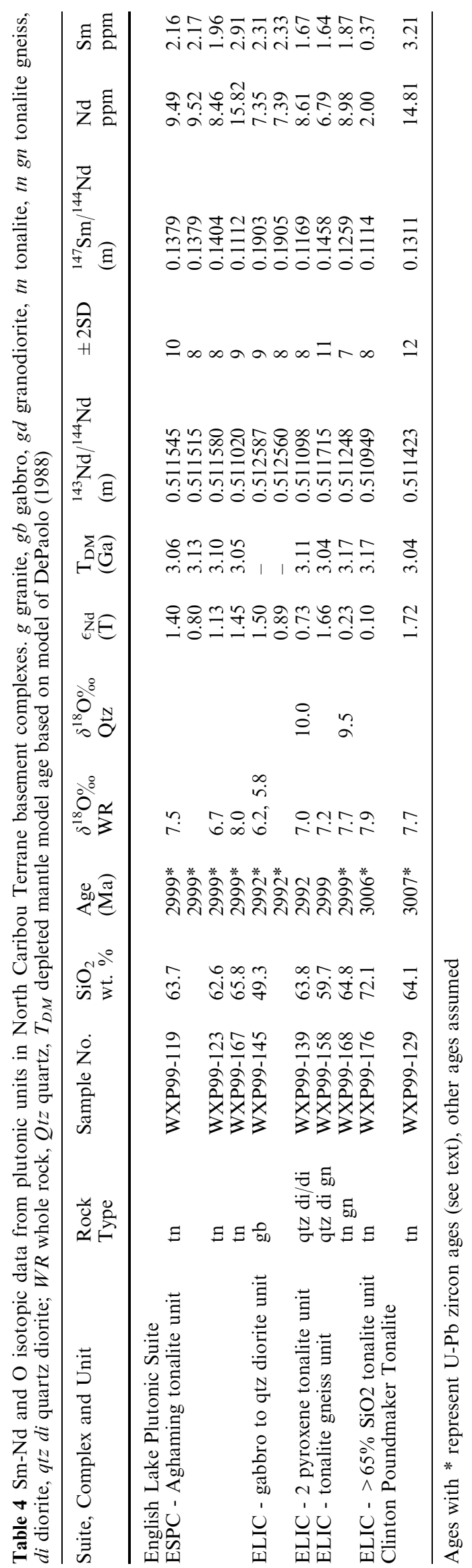

